\title{
Adenosine, an endogenous distress signal, modulates tissue damage and repair
}

\author{
BB Fredholm ${ }^{\star 1}$
}

Adenosine is formed inside cells or on their surface, mostly by breakdown of adenine nucleotides. The formation of adenosine increases in different conditions of stress and distress. Adenosine acts on four G-protein coupled receptors: two of them, $A_{1}$ and $A_{3}$, are primarily coupled to $G_{i}$ family $G$ proteins; and two of them, $A_{2 A}$ and $A_{2 B}$, are mostly coupled to $G_{s}$ like $G$ proteins. These receptors are antagonized by xanthines including caffeine. Via these receptors it affects many cells and organs, usually having a cytoprotective function. Joel Linden ${ }^{1}$ recently grouped these protective effects into four general modes of action: increased oxygen supply/demand ratio, preconditioning, anti-inflammatory effects and stimulation of angiogenesis. This review will briefly summarize what is known and what is not in this regard. It is argued that drugs targeting adenosine receptors might be useful adjuncts in many therapeutic approaches.

Cell Death and Differentiation (2007) 14, 1315-1323; doi:10.1038/sj.cdd.4402132; published online 30 March 2007

\section{Adenosine Formation and Adenosine Levels}

Adenosine is always present both within and outside cells, since it is at a crossroads between different metabolic pathways. Levels of adenosine in cells and tissue fluids is in the nanomolar range under physiological conditions (estimates range between ten and a few hundred nanomolar), but rise substantially in different forms of cellular distress (see Figure 1). Adenosine is mainly formed by the breakdown of intra- or extracellular adenine nucleotides, ${ }^{2}$ but hydrolysis of $S$-adenosyl homocysteine also contributes. ${ }^{3}$ Levels of intracellular ATP are high (several millimolar). Therefore, transient or permanent damage of cell membranes during trauma will lead to massive increase in extracellular ATP, and rapid formation of adenosine (Figure 1). There is also regulated release of ATP. It can be released by exocytosis, both when there is complete fusion between vesicle and cell membrane, and when it is transient, so-called 'kiss-and-run' release ${ }^{4}$; it can be released through connexin hemichannels ${ }^{5}$; and it is released from cell membranes subjected to stretch. ${ }^{6}$ The phosphate groups of extracellular ATP are rapidly split off by ecto-enzymes working in concert, first via nucleoside triphosphate diphosphohydrolases similar to $\mathrm{CD} 39,{ }^{7}$ followed by hydrolysis via ecto-5'-nucleotidase, $\mathrm{CD} 73 .{ }^{8}$

Adenosine formation intracellularly increases with increasing cellular workload and the increase is related to indices such as oxygen consumption ${ }^{9}$ and excitatory transmitter release. ${ }^{10}$ Adenosine formed intracellularly will be transported out of the cells by means of efficient equilibrative transporters. There are inhibitors for these transporters, including the drug dipyridamole. These inhibitors will increase extracellular adenosine if it derives from extracellular breakdown of adenine nucleotides, but decrease it if adenosine is formed intracellularly. In a tissue there may be little effect of such inhibitors, because both pathways occur simultaneously. For example, in both neurons and glial cells that are exposed to metabolic deprivation adenosine release is increased, but the mechanism may be partly different: neurons appear to mostly increase intracellular adenosine, whereas glial cells export adenine nucleotides. ${ }^{11}$ An inhibitor of the equilibrative transporter would then be expected to reduce adenosine release from neurons, increase it from glial cells, and probably not affect total adenosine release very much.

Two enzymes play a key role in catabolizing adenosine: adenosine deaminase (ADA) and adenosine kinase (ADK). The former is a high capacity and high $\mathrm{Km}$ enzyme, the latter is low capacity and low $\mathrm{Km}$. When ADA is blocked or genetically deleted, the capacity of ADK is exceeded and adenosine levels can rise markedly (at least in some tissues). ${ }^{12}$ This is probably part of the reason why one form of severe combined immunodeficiency is caused by an ADA deficiency. ADK is critically important in maintaining the physiological levels of adenosine low, and also in maintaining depots of adenine nucleotides. ${ }^{13}$ Targeted deletions of these enzymes, as well as drugs inhibiting them are important tools to determine roles of adenosine.

${ }^{1}$ Department of Physiology and Pharmacology, Karolinska Insitutet, Stockholm, Sweden

*Corresponding author: BB Fredholm, Department of Physiology and Pharmacology, Karolinska Insitutet, S-171 77 Stockholm, Sweden. Tel: + 46852487939 ;

Fax: + 468341 280; E-mail: bertil.fredholm@ki.se

Keywords: hypoxia; vasodilatation; preconditioning; angiogenesis; lymphocyte; neurodegeneration

Abbreviations: ADA, adenosine deaminase; ADK, adenosine kinase; COX-2, cycloxygenase type II (inducible); BDNF, brain-derived neurotrophic factor; cAMP, cyclic adenosine $3^{\prime}, 5^{\prime}$-monophosphate; HIF- $1 \alpha$, hypoxia-inducible factor $1 \alpha$; IFN $\gamma$, interferon gamma; IL (-4; -12; -13), interleukin (-4; 12; 13); k-0, knock out; NF- $\kappa$ B, nuclear factor kappa B; NK cell, natural killer cell; TLR, Toll-like receptor; VEGF $(-A ;-B),(-1 ;-2)$; VEGFR $(-1 ;-2)$, vascular endothelial growth factor receptor $(-1$; -2) Received 08.1.07; revised 27.2.07; accepted 02.3.07; Edited by P Nicotera; published online 30.3.07 


\section{Adenosine Receptors}

Adenosine acts on four G-protein coupled receptors that are well conserved among vertebrates. ${ }^{14}$ Their characteristics are summarized in Table 1. Three of the adenosine receptors, $A_{1}$,

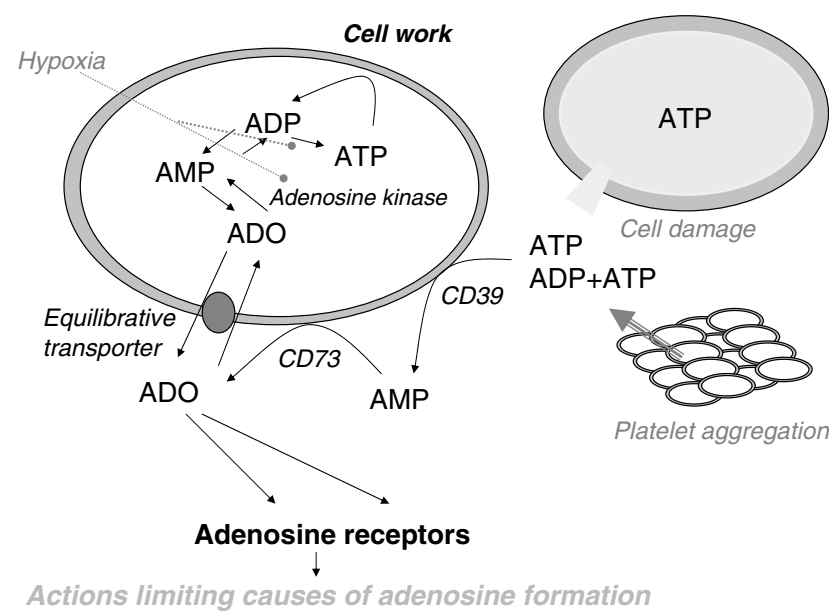

Figure 1 Some of the mechanisms regulating adenosine levels in response to physiological or pathopysiological reactions. Activation - intact line; inhibition hatched line. For further details see text
$A_{2 A}$ and $A_{2 B}$, are the major target for the most widely used of all drugs - caffeine. Already the concentrations achieved following a single cup of coffee or tea suffices to cause significant blockade of the three mentioned adenosine receptors. ${ }^{15}$ This will have biological consequences if the receptors are activated by the endogenous ligand, which happens where the receptors are very abundant and/or where adenosine levels are elevated. Mice with targeted deletions of each of the receptors exist and have been very important in the characterization of the physiological/pathophysiological roles that they play.

Adenosine in concentrations present under basal conditions are sufficient to activate $A_{1}, A_{2 A}$ and $A_{3}$ receptors, at least if they are abundantly expressed (Figure 2). By contrast, adenosine $A_{2 B}$ receptors require higher concentrations of adenosine to be significantly activated, concentrations that are believed to be present during more extreme or pathological conditions. It is also important to remember that the potency of adenosine as an agonist is very dependent on the density of receptors. For example, when the receptor number is decreased to half (as is the case in mice with only one copy of the receptor gene), about twice as much of the agonist is required to activate the receptor. ${ }^{16}$

There is evidence that various forms of stress as well as hypoxia can influence the expression of adenosine receptors.

Table 1 Summary of key properties of the four adenosine receptors with a brief summary of distribution, major roles and phenotype of relevant k-o mouse

\begin{tabular}{|c|c|c|c|c|}
\hline Receptor & Adenosine $A_{1}$ receptor & Adenosine $A_{2 A}$ receptor & Adenosine $A_{2 B}$ receptor & Adenosine $A_{3}$ receptor \\
\hline $\begin{array}{l}\text { Previous/ } \\
\text { alternative names }\end{array}$ & ADORA1; $R_{i} ; A A 1 R ; A 1 R$ & $\mathrm{~A}_{2 \mathrm{a}}, \mathrm{R}_{\mathrm{s}} ; \mathrm{AA2AR} ; \mathrm{A} 2 \mathrm{AR}$ & $\mathrm{A}_{2 \mathrm{~b}}, \mathrm{R}_{\mathrm{s}} ; \mathrm{AA2BR} ; \mathrm{A} 2 \mathrm{BR}$ & AA3R; A3R \\
\hline $\begin{array}{l}\text { Structural } \\
\text { information } \\
\text { (Accession No.) }\end{array}$ & $\begin{array}{l}\text { h } 326 \text { aa (P30542) } \\
\text { m } 326 \text { aa (Q60612) }\end{array}$ & $\begin{array}{l}\text { h } 410 \text { aa (P29274) } \\
\text { m } 409 \text { aa (UO5672) }\end{array}$ & $\begin{array}{l}\text { h } 328 \text { aa (P29275) } \\
\text { m } 332 \text { aa (UO5673) }\end{array}$ & $\begin{array}{l}\text { h } 328 \text { aa (P29275) } \\
\text { m } 332 \text { aa (UO5673) }\end{array}$ \\
\hline $\begin{array}{l}\text { Chromosomal } \\
\text { location }(\mathrm{h})\end{array}$ & $1 q 32.1$ & $22 q 11.2$ & $17 p 11.2-12$ & $17 \mathrm{p} 11.2-12$ \\
\hline Selective agonists & CPA, CCPA, CHA; S-ENBA & $\begin{array}{l}\text { CGS 21680, HE-NECA, } \\
\text { CV-1808, CV-1674, } \\
\text { ATL146e }\end{array}$ & $\begin{array}{l}\text { None readily available. } \\
\text { (LUF } 5853 \text { very potent } \\
\text { and selective) }\end{array}$ & 2-Cl-IB-MECA \\
\hline $\begin{array}{l}\text { Selective } \\
\text { antagonists }\end{array}$ & $\begin{array}{l}\text { DPCPX; 8- } \\
\text { cyclopentyltheophylline, } \\
\text { WRC0571 }\end{array}$ & $\begin{array}{l}\text { SCH } 58261 \text { ZM241385 } \\
\text { (KF 17387, CSC) }\end{array}$ & MRS1754, (enprofylline) & $\begin{array}{l}\text { MRS 1220, MRE 3008- } \\
\text { F20, MRS 1191; MRS } \\
\text { 1523; VUF } 8504\end{array}$ \\
\hline Radioligands & $\begin{array}{l}{\left[{ }^{3} \mathrm{H}\right]-\mathrm{DPCPX} ;\left[{ }^{3} \mathrm{H}\right]-\mathrm{CHA}} \\
{\left[{ }^{3} \mathrm{H}\right]-\mathrm{CCPA}}\end{array}$ & $\begin{array}{l}{\left[{ }^{3} \mathrm{H}\right]-\mathrm{CGS} 21680 ;\left[{ }^{3} \mathrm{H}\right]-\mathrm{SCH}} \\
58261 ;\left[{ }^{3} \mathrm{H}\right]-\mathrm{ZM}-241385\end{array}$ & $\begin{array}{l}\left({ }^{3} \mathrm{H}\right]-\mathrm{ZM}-241385 \\
\left.\left[{ }^{3} \mathrm{H}\right]-\mathrm{DPCPX}\right)\end{array}$ & {$\left[{ }^{3} \mathrm{H}\right]-$ MRE $3008-F 20$} \\
\hline $\begin{array}{l}\text { G-protein coupling } \\
\text { Some recognized } \\
\text { physiological } \\
\text { function(s) }\end{array}$ & $\begin{array}{l}\mathrm{G}_{\mathrm{i}}, \mathrm{G}_{\mathrm{o}} \\
\text { Bradycardia; inhibition of } \\
\text { lipolysis; reduced glomerular } \\
\text { filtration; tubero-glomerular } \\
\text { feedback; antinociception; } \\
\text { reduction of sympathetic and } \\
\text { parasympathetic activity; } \\
\text { presynaptic inhibition; neuronal } \\
\text { hyperpolarization; ischemic } \\
\text { preconditioning }\end{array}$ & $\begin{array}{l}\mathrm{G}_{\mathrm{s}}, \mathrm{G}_{\text {olf }} \\
\text { Regulation of sensorimotor } \\
\text { integration in basal ganglia; } \\
\text { inhibition of platelet } \\
\text { aggregation and } \\
\text { polymorphonuclear } \\
\text { leukocytes; vasodilatation, } \\
\text { protection against ischemic } \\
\text { damage; stimulation of } \\
\text { sensory nerve activity }\end{array}$ & $\begin{array}{l}\mathrm{Gs}, \mathrm{G}_{\mathrm{q}} \\
\text { Relaxation of smooth } \\
\text { muscle in vasculature } \\
\text { and intestine; inhibition } \\
\text { of monocyte and } \\
\text { macrophage function, } \\
\text { stimulation of mast cell } \\
\text { mediator release (some } \\
\text { species) }\end{array}$ & $\begin{array}{l}\mathrm{G}_{\mathrm{i}} \\
\text { Enhancement of mediator } \\
\text { release from mast cells } \\
\text { (some species); } \\
\text { preconditioning (some } \\
\text { species) }\end{array}$ \\
\hline K-o phenotype & $\begin{array}{l}\text { Anxiety, hyperalgesia, } \\
\text { decreased tolerance to } \\
\text { hypoxia, loss of tubero- } \\
\text { glomerular feedback, altered } \\
\text { insulin secretion, increased } \\
\text { lipolysis, increased } \\
\text { susceptibility to seizures, loss } \\
\text { of preconditioning in several } \\
\text { tissues }\end{array}$ & $\begin{array}{l}\text { Anxiety, hypoalgesia, } \\
\text { hypertension, increased } \\
\text { tolerance to ischemia, } \\
\text { altered sensitivity to motor } \\
\text { stimulant drugs, decreased } \\
\text { platelet aggregation }\end{array}$ & $\begin{array}{l}\text { Hyperinflammation; } \\
\text { vascular adhesion }\end{array}$ & $\begin{array}{l}\text { Altered inflammatory } \\
\text { reactions, decreased } \\
\text { edema, altered release of } \\
\text { inflammatory mediators }\end{array}$ \\
\hline
\end{tabular}

k-o, knock out. 


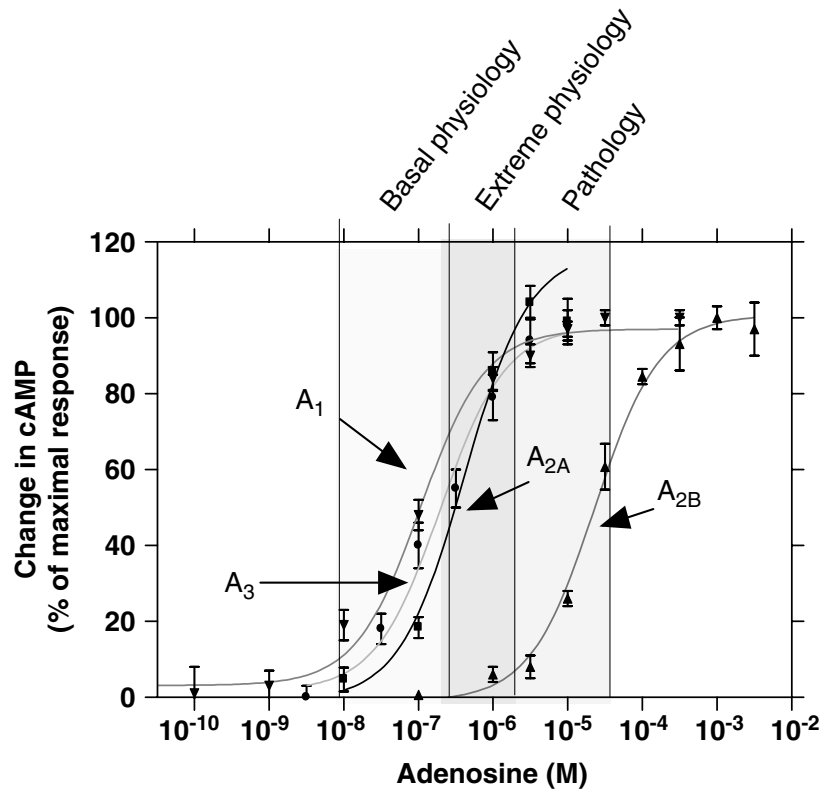

Figure 2 The ability of adenosine to activate the adenosine receptors. The human adenosine receptors were constitutively expressed in Chinese hamster ovary cells (20-150 000 receptors per cell). The potency of adenosine to stimulate or inhibit the formation of CAMP was examined after blocking the transport of adenosine into the cells. The experimental data are related to data measuring adenosine levels in body fluids under basal physiological conditions, in extreme physiological conditions (heavy work, mild hypoxia, etc.), or in pathophysiological conditions (ischemia, tissue damage, etc.)

Regulation of $A_{1}, A_{2 A}$ and $A_{3}$ receptor expression by various immune-related stimuli are briefly touched upon below. Expression of adenosine receptors in nerve cells is also regulated by nerve activity. Hypoxia, which as noted above, can regulate adenosine levels in many ways and can also stimulate the expression of adenosine receptors. For example, hypoxia can directly increase the expression of $A_{2 B}$ receptors ${ }^{17}$ because there is a canonical hypoxia-inducible factor $1 \alpha(\mathrm{HIF}-1 \alpha)$ binding site in the promoter. $A_{2 A}$ receptor expression is not generally increased by hypoxia, but it must be remembered that several of the adenosine receptors have multiple promoters regulating alternative transcripts, and there could be cell differences in the regulation by hypoxia. ${ }^{18}$ Furthermore, in at least some cells adenosine receptor trafficking is stimulated by hypoxia ${ }^{19}$ and this is, interestingly, dependent on the phenotype of the cell.

\section{Increasing Oxygen Supply and/or Decreasing Oxygen Demand by Adenosine}

Vascular reactivity. The ability of adenosine to increase blood flow through tissues has long been known and adenosine has been proposed to be a major mediator of the adaptation of blood flow to metabolic demand. ${ }^{20}$ Most blood vessels dilate in response to adenosine. Major exceptions are the afferent arterioles of the kidney, which contract in response to adenosine coming from the interstitium. ${ }^{21}$ This vasoconstriction is mediated via adenosine $A_{1}$ receptors. The $A_{1}$ receptor-mediated vasoconstriction is part of an important feedback circuit whereby excess transport work in the kidney tubules cause enhanced adenosine formation. The adenosine is transported to the glomeruli where it reduces blood flow and thereby reduces tubular transport work. This is the well-known tubuluglomerular feed back mechanism, and it absolutely requires adenosine $A_{1}$ receptors. ${ }^{22,23}$ It has been suggested that $A_{1}$ receptors can mediate constriction also in other vascular beds, but these studies were carried out on aorta, hardly known for its role in regulating blood flow, ${ }^{24}$ and evidence for a major role of $A_{1}$ receptors in regulating vascular tone is poor. ${ }^{16,25}$

By contrast, there is excellent evidence that adenosine $A_{2 A}$ and $A_{2 B}$ receptors do regulate vascular reactivity. Adenosine, acting on these receptors, mediates vasodilatation, partly by a direct action on the smooth muscle cells, partly endothelium mediated. There is some increase in blood pressure in $A_{2 A}$ knock-out (k-o) mice. ${ }^{26}$ Besides acting directly at blood vessels adenosine, $A_{2 A}$ receptors can regulate local blood flow by reducing platelet aggregation ${ }^{26}$ and the adherence of leucocytes to endothelial cells (see below).

Temperature regulation. Body temperature in mammals is precisely regulated and neurons in the preoptic area play a particularly important role. There is intriguing evidence that this central temperature control is of major importance in the life span. ${ }^{27}$ Perhaps body temperature affects proteins, including the so-called heat-shock proteins, that regulate i.a., the apoptotic pathways. ${ }^{28}$ But this remains to be elucidated. It is, however, clear that body temperature is intimately connected with activity of the immune system and also with the rate of oxidative metabolism. Therefore it is possibly important that adenosine $A_{1}$ receptor activation is one of the most efficient means of lowering body temperature, ${ }^{16}$ and that mice lacking adenosine $A_{1}$ receptors have elevated body temperatures and decreased survival. ${ }^{25,29}$ Actually, the magnitude of the temperature reduction caused by systemic administration of an adenosine $A_{1}$ agonist could be used to adequately genotype mice into wild type, heterozygote and $\mathrm{k}-\mathrm{o} .{ }^{16}$

Decreasing cell work. An effect of adenosine on the amount of cellular work has been reported for many cells and organs. Sometimes the effect is indirect. For example, by reducing renal blood flow, tubular transport work is reduced. In other cases effects are more direct. The clearest examples may relate to the nervous system. Here the adenosine $A_{1}$ receptor, widely distributed in the brain, acts via two major mechanisms: inhibition of release of especially excitatory neurotransmitters and hyperpolarization of nerves leading to decreased rates of firing. ${ }^{30}$ The first is achieved by limiting calcium entry in the nerve terminals, whereas the second by increasing potassium conductance in the cell body and dendrites. The adenosine levels are increased not only by metabolic stimuli such as hypoxia (see above) but also by activation of excitatory neurotransmission, especially by activating NMDA receptors $^{16,31}$ (see also Figure 3). The release of adenosine during hypoxia limits the excitatory stimulation so that the neurons can survive the decreased energy 


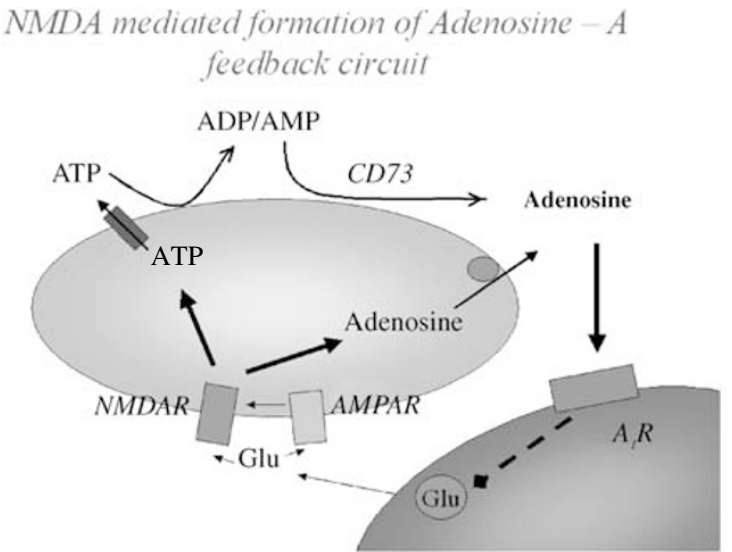

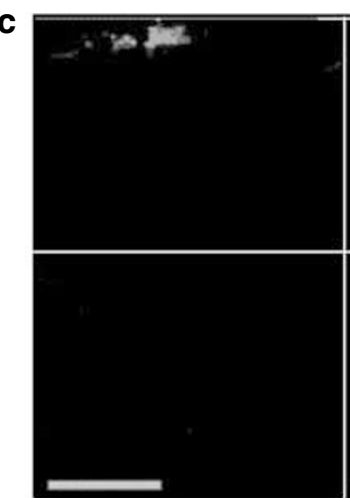

WT

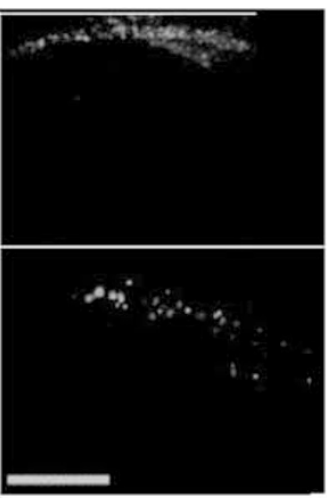

$\mathrm{A}_{1} \mathrm{~K}-\mathrm{O}$

b

$$
\text { - }+/+(n=6) \quad \Delta \quad-/-(n=6)
$$

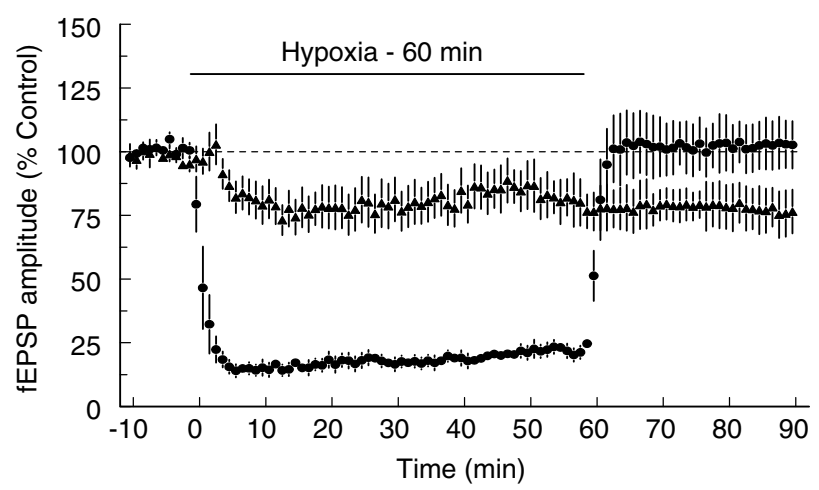

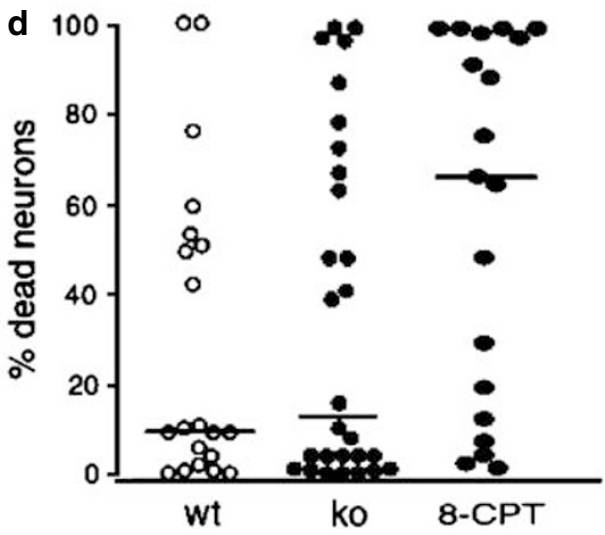

Figure 3 Adenosine $A_{1}$ receptors regulate excitatory neurotransmission and limit cell death after seizures, but play minimal role in postischemic cell death. (a) $A$ glutamatergic nerve releases glutamate that acts on AMPA and NMDA receptors on the post-junctional neuron. NMDA receptors, which are only activated upon more intense stimulation, lead to release of adenosine into the extracellular environment. It is not known if this is caused primarily by release of ATP or adenosine. Adenosine is acting on the glutamatergic nerve ending to limit further excessive glutamate release. This provides a feedback regulation of excitatory neurotransmission. (b) Excitatory neurotransmission in the hippocampus is very constant, provided energy supply is maintained. If, however, oxygen supply is limited, the magnitude of the evoked response goes down quickly and is maintained at a low level until oxygen is readmitted. The magnitude of the transmission is then restored to the control value. Thus, the level of excitation is reduced to a level that can be maintained in the face of limited amounts of energy. However, if there are no adenosine $A_{1}$ receptors, this adaptive reaction no longer occurs: the magnitude of the excitatory response is reduced less and much later, and there is no restoration, suggesting irreversible damage. Data from ${ }^{16}$. (c) Adenosine $A_{1}$ receptors limit the negative consequences of excitatory neurotransmission. In the absence of adenosine $A_{1}$ receptors, cell death (determined by TUNEL staining) following induction of status epilepticus by injection of kainate in one hippocampus is spread to the other hippocampus. There are also more dead cells on the ipsilateral side. Data from ${ }^{33}$. (d) $A_{d e n o s i n e ~} A_{1}$ receptors do not play a critical role in limiting the extent of postischemic cell damage in the brain. However, a non-selective receptor antagonist does exacerbate the damage, indicating that other receptors are important. This implies that adenosine does not influence ischemic neurodegeneration by limiting excitatory neurotransmission. Data from ${ }^{73}$

supply. ${ }^{16}$ Similarly, the release of adenosine by strong excitatory stimulation limits the risk for excitotoxicity (Figure 3).

In seizures, including epileptic, excitatory neurotransmission dominates and this is believed to be important for the loss of neurons following epileptic seizures. ${ }^{13}$ There is now very good evidence that adenosine, acting on $A_{1}$ receptors, plays an important role in limiting seizures, and seizure-dependent cell death. ${ }^{13}$ ADK present mainly in astrocytes could play a particularly important role in decreasing adenosine levels and thereby promoting cell death. ${ }^{13}$ Brain trauma can lead to astrogliosis, and by virtue of overexpression of ADK to reduced adenosine $A_{1}$ receptor-mediated inhibition of excitotoxicity. Indeed, cell death after seizures increases markedly in the absence of adenosine $A_{1}$ receptors. ${ }^{32,33}$
Systemic adaptation to hypoxia. Adenosine is also important in the adaptive changes in respiration and circulation triggered by hypoxia sensing cells in the carotid body. Adenosine receptors of the $A_{2 A}$ type are found in type I cells of the carotid body. ${ }^{34}$ These receptors play an important role in mediating respiratory stimulation to acute hypoxia. ${ }^{35}$ Interestingly, these receptors appear to functionally interact with dopamine $D_{2}$ receptors, just as in the basal ganglia $\left(\mathrm{see}^{15}\right)$. The increased firing in the afferent nerves from the carotid body stimulates respiration and also increases blood pressure. This response has been suggested to contribute to the cardiovascular morbidity of patients with sleep apnoea. More prolonged hypoxia will instead lead to respiratory depression. This is at least partly mediated via $A_{1}$ receptors. ${ }^{16}$ The switch between hypoxic stimulation and 
depression is altered during early development, perhaps in parallel with regulated expression of the adenosine receptors. $^{34}$

\section{Preconditioning}

A prior hypoxic/ischemic insult in the same or in another organ can provide protection against a subsequent ischemic insult. This is a general phenomenon called preconditioning and can occur both acutely and over a long period of time. ${ }^{36,37}$ Late preconditioning depends on the expression of different gene products, but perhaps some of the same signaling events are involved in both early and late preconditioning. Adenosine has been clearly implicated (together with other ligands acting at $\mathrm{G}_{\mathrm{i}}$-coupled receptors) in mediating such preconditioning. ${ }^{38}$ There is clear evidence that adenosine $A_{1}$ receptors are not only targets for exogenous agonists, but also is involved in mediating the physiological phenomenon itself, at least in mice. ${ }^{39}$ This is true not only for the acute, so-called classical preconditioning, ${ }^{39}$ but also for so-called remote preconditioning, where ischemia in another organ (in this case brain) leads to cardioprotection. ${ }^{40}$ The signaling pathways remain poorly understood and the mere fact that preconditioning via adenosine can occur in many different organs in the body indicates that very tissue-specific processes are unlikely to play a major role.

\section{Angiogenesis}

Drugs aiming at inhibiting or stimulating angiogenesis could benefit large patient populations. ${ }^{41}$ Indeed, blockade of angiogenesis provides additional benefit in tumor therapy. ${ }^{42}$ The formation of functional blood vessels appears to require many different factors acting in an orderly cascade. Of these factors particular attention has been given to vascular endothelial growth factor (VEGF) (particularly VEGF-A and VEGF-B) that acts on two receptors, vascular endothelial growth factor receptor 1 (VEGFR-1) and VEGFR-2. ${ }^{43}$ The fact that many of the same factors, including adenosine, play a role in regulating blood flow, angiogenesis and the immune system ${ }^{44}$ is probably not only conceptually but also therapeutically important. Not only does this indicate the connection between multiple processes not normally considered together, but it also suggests that only by hitting a combination of targets can an appropriate effect be achieved. There is now strong evidence that adenosine, in addition to controlling oxygen delivery acutely by regulating vascular tone, serves a long-term role by enhancing vascular growth in areas with reduced oxygen tension. ${ }^{45}$ Thus, adenosine in physiologically relevant concentrations can stimulate migration and proliferation of endothelial cells. Furthermore, adenosine can stimulate the expression of VEGF in many types of cells. ${ }^{45}$ This may be achieved by stimulating $A_{2 A}$ and/or $A_{2 B}$ receptors and may utilize another signaling pathway than $\mathrm{HIF}-1 \alpha$ activated by hypoxia, ${ }^{45,46}$ but there is also evidence for a role of HIF- 1 and the $A_{3}$ receptor when other cells are studied. ${ }^{47}$ There is reason to believe that the relative role(s) of these receptors differ with the cell type. Although adenosine may contribute rather little to the increase in VEGF induced by hypoxia, it may contribute as much as $50 \%$ to angiogenesis. ${ }^{45}$ This could mean that adenosine acts also independently of VEGF, something that is not unlikely given the involvement of multiple cell types and multiple angiogenetic factors. ${ }^{41-43}$ For example, the effects of adenosine on macrophages regulating them in a state-dependent way (see below) could be an important factor also in angiogenesis.

Angiogenesis is also important in brain repair after stroke. ${ }^{43}$ Therefore angiogenic factors, including VEGF and adenosine, may be useful in therapy. Here, as elsewhere, it is important to use an approach that generates functional vessels that do not show excessive leakage. ${ }^{43}$ VEGF is also implicated in adult neurogenesis and in the proliferation of astrocytes, and VEGF has marked neurotrophic effects. ${ }^{43}$ This is likely to be of pathophysiological significances as targeted deletion of the relevant VEGF receptor is associated with increased infarct volume and more neurological deficits after ischemia. ${ }^{43}$ Since such effects are not an unmixed blessing, it is again possible that a combination of targets may be more useful than just hitting one and that one or more of the adenosine receptors could be part of a new therapeutic goal. This possibility has been explored for wound healing as it has been shown that activation of adenosine $A_{2 A}$ receptors can promote wound healing partly by promoting angiogensis and vasculogenesis. $^{48}$

\section{Immune System}

Adenosine is known to regulate many immune functions. ${ }^{12,49-52}$ Thus, many of the cells of the immune system have abundant adenosine receptors, and endogenous adenosine influences their function. ${ }^{49,51,53}$

Neutrophil leukocytes are important in the first line of defence against pathogens. Adenosine and the precursor ATP control neutrophil function. ${ }^{49,51,53}$ Neutrophils release both ATP and adenosine following activation (e.g., reference ${ }^{54}$ ) and they express CD39 and CD73, hence rapidly convert ATP to adenosine.

They express all four adenosine receptors expressed, but the number of receptors may differ with the activation state (e.g., see reference ${ }^{54}$ ). $A_{1}$ receptors have been shown to enhance adhesion, but the effect may be mainly due to $A_{1}$ receptors on endothelial cells rather than on the neutrophils themselves. Activation of adenosine $A_{2 B}$ receptors on endothelial cells instead inhibits leucocyte adhesion and this response appears to be operating already under basal physiological circumstances as $\mathrm{A}_{2 \mathrm{~B}}$ receptor k-o mice have increased expression of endothelial adhesion molecules. ${ }^{55}$ The $A_{2 B}$ receptors on endothelial cells are also important maintaining a barrier to leukocyte migration. Perhaps the first neutrophils that pass through the endothelium provide the signal to close the barrier, thereby limiting the number of neutrophils that enter a tissue in any specific section of the vasculature.

$A_{2 A}$ receptors on neutrophils play an important role in regulating some of the surface molecules on neutrophils that mediate vascular cell adhesion molecule-1-dependent adhesion. There are also $A_{2 A}$ receptors on endothelial cells that may act synergistically (but on endothelial cells $A_{2 B}$ receptors may be even more important). Activation of $A_{2 A}$ receptors on neutrophils also potently inhibits phagocytosis, degranulation 
and formation of oxygen-centered free radicals important in bactericidal functions. ${ }^{49,51,53}$ Adenosine via $A_{2 A}$ receptors also reduces leukotriene formation while it increases cycloxygenase type II (inducible)-mediated prostanoid formation. In all these ways, adenosine can also protect endothelium against neutrophil-mediated damage. Generation of proinflammatory cytokines and chemokines by neutrophils is suppressed by $A_{2 A}$ receptor stimulation. Migration of neutrophils has also long been known to involve adenosine and ATP. Recently it was shown that migration of neutrophils depends on release of ATP, which activates an ATP receptor as well as adenosine $A_{3}$ receptors on the leading edge of the migration neutrophil leukocyte. ${ }^{56}$ Indeed, the adenosine $A_{3}$ receptors were found to traffic from intracellular sites to the leading edge of the stimulated cell. It has previously been shown that adenosine receptors coupling to $G_{i}$ proteins can act synergistically with $\mathrm{P} 2 \mathrm{Y}$ receptors sensing ATP and coupling to $G_{q}$ proteins. ${ }^{57}$ By contrast, activation of $A_{2}$ receptors elsewhere on the neutrophil may instead facilitate retraction of membrane at the receding end. Thus, apparently opposing adenosine receptors may actually work in concert.

During hypoxia adenosine, formed from breakdown of released ATP by CD39 and CD73, provides an important signal to limit excessive infiltration of neutrophils and subsequent tissue damage. ${ }^{54}$ It was found that in both CD39 and CD73 null mice neutrophil accumulation in hypoxia was much enhanced, thereby proving that the adenosine that inhibitors neutrophils derives from released ATP. Hypoxia may actually increase not only ATP release but also expression of CD39 and CD73, as well as reduce the expression of nucleoside transporters that in this condition tend mainly to reduce adenosine levels. Thus adenosine is a very important modulator that tends to keep the activation of neutrophils low and thereby to prevent, for example, excessive vascular damage.

Monocytes and macrophages. The mononuclear phagocytic cells are found in the blood stream as monocytes or in tissues as macrophages (or microglial cells in the brain). They are the major producers of inflammatory mediators and are hence critically important in deciding the course of inflammatory processes. In tissues they display very different phenotypes depending on earlier exposure to, for example, inflammatory stimuli. ${ }^{58}$ They can be activated via, for example, Toll-like receptors (TLR) to produce cytokines and microbicidal molecules, or by cytokines such as interleukin (IL)-4 and IL-13 or by phagocytosis of apoptotic cells to essentially counteract classical activation. ${ }^{51}$ These cells express CD39 as well as CD73 and they can release both ATP and adenosine upon activation. The expression of CD73 and CD39 increases upon differentiation. They also express all four adenosine receptor types, but the expression level varies with the phenotype. ${ }^{51}$

There are a large number of studies implicating adenosine in monocyte/macrophage/microglial cell function. These reports are sometimes conflicting, which is probably not surprising as it is difficult to study the important tissue resident cells in isolation in a defined activation state. Species differences could also be a complicating issue. It does seem clear that migration of monocytes into tissues is reduced by adenosine via $A_{2 A}$ receptors. ${ }^{51,58}$ Indeed, in mice lacking $\mathrm{CD73}$, and hence having reduced adenosine levels, macrophage levels in tissues increased after inflammatory stimuli. ${ }^{59}$ Many studies also indicate that TLR-induced activation of nuclear factor kappa $\mathrm{B}(\mathrm{NF}-\kappa \mathrm{B})$ is reduced by adenosine acting at $A_{2 A}$ receptors and the production of proinflammatory IL-12 and tumor necrosis factor $\alpha,{ }^{51,58}$ but other receptors may also contribute. Perhaps adenosine is involved in switching to the alternatively activated macrophages that are involved in repair. Indeed, adenosine seems to act in concert with other factors induced by hypoxia such as HIF $1 \alpha$ in promoting formation of repair factors such as VEGF and brain-derived neurotrophic factor. Few studies in vitro implicate adenosine $A_{1}$ receptors. However, two in vivo studies using $A_{1} k-0$ mice have provided evidence that $A_{1}$ receptors, probably on macrophages, play a protective role in inflammation. ${ }^{60,61}$

Dendritic cells. The dendritic cells are antigen-presenting cells that function to activate $T$ cells. Both adenosine and its precursor ATP are known to influence dendritic cells. ${ }^{51}$ Like the macrophages, the expression of adenosine receptors on dendritic cells depends on the phenotype. ${ }^{62}$ Upon maturation, the $A_{2 A}$ receptor becomes upregulated and they apparently mediate inhibition of proinflammatory cytokine production. So far little is known about the role(s) of adenosine receptors (if any) in regulating the processing of antigen and its presentation. There is recent data suggesting a novel type of dendritic cell - the interferon-producing killer dendritic cell - with a potentially very important role in tumor immunosurveillance. It will be important to learn how adenosine affects these cells.

Lymphocytes. It has been known for a long time that adenosine can regulate several lymphocyte functions. All adenosine receptors can be detected in T lymphocytes, but expression of $A_{1}$ receptors is low. ${ }^{51}$ The bulk of the interest centers on $A_{2 A}$ receptors as it has been shown that mice with targeted deletions of $A_{2 A}$ receptors have a very altered $\mathrm{T}$ lymphocyte-mediated inflammatory response, ${ }^{63}$ and because drugs that activate adenosine $A_{2 A}$ receptors strongly reduce the $\mathrm{T}$ cell-mediated inflammatory response in a variety of tissues. ${ }^{52,64,65}$ However, $A_{2 B}$ receptors also appear to play a role. These receptors couple to the same $G$ protein as $A_{2 A}$ receptors and stimulation of cyclic adenosine $3^{\prime}, 5^{\prime}$-monophosphate (cAMP) figures prominently in the signaling cascade, but nevertheless the ultimate effects can sometimes be quite different. Perhaps this is due to differences in the proteins with which the receptors associate. Interestingly, activation of T-cell receptors leads to a rapid upregulation of $A_{2 A}$ receptors and this is associated with inhibited interferon $\gamma$ release by these cells. ${ }^{66}$ There was a complete absence of adenosine effect in $A_{2 A}-1-$ mice, and it was reduced to about half in $A_{2 A}+/-$ mice. The latter emphasizes the importance of receptor number in determining the potency of the endogenous agonist. There are also reports of the adenosine-mediated alteration in the release of several other cytokines, and of cytokine-mediated changes in ecto-ADA. The possibility exists that adenosine, 
acting mostly on $A_{2 A}$ receptors, may redress imbalances in balance between the two subsets of T-helper cells. ${ }^{51}$

Elevation of adenosine levels by genetic or drug-induced $A D A$ deficiency leads to reduced $B$-cell responses. Again $A_{2 A}$ (and possibly $A_{2 B}$ receptors) are most strongly implicated. The inhibition may be related to a CAMP-mediated inhibition of $\mathrm{NF}-\kappa \mathrm{B}$, via inhibition of inhibitor of kappa $\mathrm{B}$ phosphorylation. ${ }^{12}$ There is also evidence that natural killer (NK) cells may be regulated by adenosine. ${ }^{51}$ Both $A_{1}$ and $A_{2 A / 2 B}$ receptors are suggested to play a role, perhaps via opposing actions on NK cell cAMP levels. Most studies have, however, used relatively non-selective agonists and much remains to be carried out to understand the different role(s) played by the different receptors. Recent data show the critical role of NKT cells, and of the $A_{2 A}$ receptors the possess, in mediating injury after ischemia and reperfusion. ${ }^{67}$ Thus, a major part of the liver damage after prolonged ischemia and reperfusion depends on NKT cells and on interferon gamma (IFN $\gamma)$. The NKT celldependent liver damage can be virtually eliminated by administering an agonist at $A_{2 A}$ receptors. ${ }^{67}$ Furthermore, the release of IFN $\gamma$ by NKT cells was abolished by $A_{2 A}$ stimulation. ${ }^{67}$

\section{Some Examples}

Tumor defense. NK cells as well as cytotoxic T cells are believed to play a role in defense against tumor growth. A growing tumor is expected to produce a region of relative hypoxia, and also to release adenine nucleotides by various means, including induced death of cells. This microenvironment will be 'hostile' to the immune cells involved in surveillance, because it will generate elevated adenosine, which by activation of adenosine receptors will inhibit the activity of the immune cells. ${ }^{68}$ Indeed, adenosine levels are higher within the tumor, and at its outer perimeter, than in surrounding tissues. ${ }^{68}$ Immunogenic melanoma or lymphoma cells transplanted to mice lacking $A_{2 A}$ receptors grew much more slowly than when transplanted into wildtype mice. The k-o mice survived much better. When nonimmunogenic tumors were transplanted there was no difference in rate of growth or in survival. ${ }^{68} \mathrm{~A}$ drug that blocks $A_{2 A}$ receptors could mimic the effect of the k-o. Even the non-selective antagonist caffeine had protective effects, for example, on metastases. ${ }^{68}$ Tumors also grew faster in mice lacking the receptor for IFN $\gamma$. This fact combined with the known ability of adenosine to reduce IFN $\gamma$ production via $A_{2 A}$ (and $A_{2 B}$ ) receptors provided a good explanation for the altered tumor growth. ${ }^{68}$ Another contributing factor, which was covered before, is that $A_{2 A}$ receptors are involved in angiogenesis. The selective, local inactivation of $A_{2 A}$ receptors may therefore help to boost the host defense against tumor growth. Tumor tissue itself is also regulated by factors such as HIF $1 \alpha$ and NF- $\kappa \mathrm{B}$, and therapy directed toward these targets in immune cells may backfire. Again much additional work is needed.

Airway responsiveness. There is also considerable interest in the role of adenosine in inflammatory conditions in the lung - asthma and chronic obstructive lung disease. ${ }^{69-71}$
Part of the reason for this is that the adenosine antagonist caffeine has been known since the work of Slater in the 19th century to be a usueful therapeutic agent, replaced in the middle of last century by its monodemethylated metabolite theophylline. Another reason is that adenosine-induced bronchoconstriction is a diagnostic test for asthma. ${ }^{69}$ Airway epithelia continuosly release ATP at a rate of $250 \mathrm{fmol} / \mathrm{min} / \mathrm{cm}^{2}$. This leads to a local ATP level of about $1 \mu \mathrm{M}$, but also because of high exptression of ectonucleotidases to continuos formation of adenosine. ${ }^{6}$ Adenosine levels are increased in asthma and COPD and mice lacking ADA have elevated adenosine levels and pathological changes mimicking aspects of the human disease. ${ }^{71}$ Different adenosine receptors may play opposing roles. Thus, blockade of adenosine $A_{2 B}$ receptors decreases the pathological chages indicating that these receptors promote the pathology. ${ }^{72}$ By contrast, the adenosine $A_{1}$ receptor appears to play a protective role in adenosine-dependent pulmonary injury. ${ }^{61}$ Thus, in the absence of $A_{1}$ receptors increased adenosine causes much more infiltration with eosinophils, neutrophils and lymphocytes. Furthermore, adenosine $A_{1}$ receptors were upregulated in the ADA-deficient lung; there were also changes in the other adenosine receptors. By contrast, there were no adaptive changes in the other adenosine receptors when $A_{1}$ receptors were knocked out. ${ }^{39,61}$ This role of the $A_{1}$ receptor could not be easily predicted from the studies on isolated immune cells. It is, however, compatible with the results on a role of $A_{1}$ receptors in neuroinflammation related to multiple sclerosis. ${ }^{60}$ In rodents, $\mathrm{A}_{3}$ receptors are involved in mast cell degranulation, but it is not clear if this is important in humans. ${ }^{69}$

Whereas the $A_{1}$ receptor may thus reduce inflammation, at least acutely, there is some evidence that $A_{1}$ receptors may be involved in mediating bronchoconstriction. This is, however, contentious, as there are major differences between human asthma and the animal models where such an $A_{1}$ receptormediated constriction has been demonstrated. It is possible that a major reason for the adenosine $A_{1}$ receptor-mediated effects is related to sensitization of pulmonary $C$ fibers ${ }^{73}$ rather than to a direct effect on immune effector cells or smooth muscle cells.

It has even been demonstrated that oxygenation can aggravate the inflammatory reactions leading to tissue damage and acute respiratory distress. ${ }^{74}$ This response was attributed to decreased levels of endogenous adenosine activating the $A_{2 A}$ receptors on activated immune competent cells, and could be partly mimicked by an $A_{2 A}$ agonist. It was therefore proposed that oxygen therapy should be combined with the administration of an adenosine $A_{2 A}$ agonist. ${ }^{74}$ This concept is clearly related to the idea that adenosine $A_{2 A}$ agonists would be very useful in preventing various types of ischemia reperfusion damage for which there is considerable experimental support. ${ }^{65}$

Neurodegeneration. As discussed above there is excellent evidence that $A_{1}$ receptors play an important role in limiting excitatory neurotransmission in, for example, hypoxia and following seizures. It has been speculated that excitotoxicity due to excess glutamate is of major importance in cell death 
after stroke. One would therefore expect that changes in adenosine $A_{1}$ receptors should strongly influence the outcome after stroke or cerebral artery occlusion. ${ }^{30,75}$ It was therefore a major surprise when elimination of $A_{1}$ receptors was found not to affect the size of the infarct after vessel occlusion. ${ }^{76}$ This shows that at least in this particular model of ischemic neurodegeneration excitotoxicity is not a major factor. In the same study we did observe that administration of an antagonist at mainly $A_{1}$ and $A_{2 B}$ receptors did cause aggravated damage. This could be explained either if $A_{2 B}$ receptors play a hitherto unsuspected role or if the drug blocks during a critical time window when $A_{1}$ receptors do protect.

There are additional surprises. As noted above there is very good evidence that activation of $A_{2 A}$ receptors on bone marrow-derived cells can protect against ischemic damage in several organs including liver, kidney and even spinal cord. ${ }^{65}$ It was therefore unexpected when blockade of $A_{2 A}$ receptors or the targeted elimination of these receptors actually mediated protection against ischemic neurodegeneration. ${ }^{77}$ The surprise was increased by the fact that the cerebroprotection occurred particularly in regions where there are very few $A_{2 A}$ receptors. ${ }^{30}$ Even more surprising is the fact that the relevant $A_{2 A}$ receptors occur not in the brain parenchyma but derive from the bone marrow. ${ }^{78}$

Together these results emphasize that at least some of the current hypotheses regarding ischemic brain damage are too simplistic, and they also highlight a surprising differences between tissues.

\section{Conclusions}

The level of adenosine and the expression of adenosine receptors are regulated so that the signaling via one or more of the receptors increases in cellular stress and distress. Adenosine via its receptors will tend to limit the consequences of the potentially damaging stimuli. This is achieved in multiple ways. There is a strong link between adenosine and signaling in hypoxia. In different ways adenosine can increase oxygen supply and decrease oxygen demand. This can occur both in the short term and in the long term. Angiogenesis is stimulated by adenosine and adenosine mediates some forms of preconditioning. A particularly intriguing role of adenosine is in the regulation of various aspects of inflammation. The precise roles of the different receptors appear to differ in a time- and tissue-dependent manner. What is beneficial in one tissue at one time may be detrimental at another time or place. For this reason, and because adenosine plays so many roles therapeutic efforts may be frustrated.

1. Linden J. Adenosine in tissue protection and tissue regeneration. Mol Pharmacol 2005; 67 1385-1387.

2. Zimmermann $\mathrm{H}$. Extracellular metabolism of ATP and other nucleotides. Naunyn Schmiedebergs Arch Pharmacol 2000; 362: 299-309.

3. Deussen A, Lloyd HG, Schrader J. Contribution of S-adenosylhomocysteine to cardiac adenosine formation. J Mol Cell Cardiol 1989; 21: 773-782.

4. MacDonald PE, Braun M, Galvanovskis J, Rorsman P. Release of small transmitters through kiss-and-run fusion pores in rat pancreatic beta cells. Cell Metab 2006; 4 283-290.

5. Eltzschig HK, Eckle T, Mager A, Küper N, Karcher C, Weissmüller T et al. ATP release from activated neutrophils occurs via connexin 43 and modulates adenosine-dependent endothelial cell function. Circ Res 2006; 99: 1100-1108.
6. Okada SF, Nicholas RA, Kreda SM, Lazarowski ER, Boucher RC. Physiological regulation of ATP release at the apical surface of human airway epithelia. J Biol Chem 2006; 281 : 22992-23002.

7. Robson SC, Wu Y, Sun X, Knosalla C, Dwyer K, Enjyoji K. Ectonucleotidases of CD39 family modulate vascular inflammation and thrombosis in transplantation. Semin Thromb Hemost 2005; 31: 217-233.

8. Picher M, Burch LH, Hirsh AJ, Spychala J, Boucher RC. Ecto $5^{\prime}$-nucleotidase and nonspecific alkaline phosphatase. Two AMP-hydrolyzing ectoenzymes with distinct roles in human airways. J Biol Chem 2003; 278: 13468-13479.

9. Deussen A, Schrader J. Cardiac adenosine production is linked to myocardial $\mathrm{pO}_{2}$. J Mol Cell Cardiol 1991; 23: 495-504.

10. Jonzon B, Fredholm BB. Release of purines, noradrenaline, and GABA from rat hippocampal slices by field stimulation. J Neurochem 1985; 44: 217-224.

11. Parkinson FE, Xiong W, Zamzow CR. Astrocytes and neurons: different roles in regulating adenosine levels. Neurol Res 2005; 27: 153-160.

12. Hershfield MS. New insights into adenosine-receptor-mediated immunosuppression and the role of adenosine in causing the immunodeficiency associated with adenosine deaminase deficiency. Eur J Immunol 2005; 35: 25-30.

13. Boison D. Adenosine kinase, epilepsy and stroke: mechanisms and therapies. Trends Pharmacol Sci 2006; 27: 652-658.

14. Fredholm BB, IJzerman AP, Jacobson KA, Klotz KN, Linden J. International Union of Pharmacology. XXV. Nomenclature and classification of adenosine receptors. Pharmacol Rev 2001; 53: 527-552.

15. Fredholm BB, Bättig K, Holmén J, Nehlig A, Zvartau EE. Actions of caffeine in the brain with special reference to factors that contribute to its widespread use. Pharmacol Rev 1999; 51 83-133.

16. Johansson B, Halldner L, Dunwiddie TV, Masino SA, Poelchen W, Giménez-Llort L et al. Hyperalgesia, anxiety, and decreased hypoxic neuroprotection in mice lacking the adenosine A1 receptor. Proc Natl Acad Sci USA 2001; 98: 9407-9412.

17. Kong $\mathrm{T}$, Westerman KA, Faigle M, Eltzschig HK, Colgan SP. HIF-dependent induction of adenosine A2B receptor in hypoxia. FASEB J 2006; 20: 2242-2250.

18. Fredholm BB, Chern Y, Franco R, Sitkovsky M. Aspects of the general biology of adenosine A2A signaling. Prog Neurobiol 2007 (in press).

19. Arslan G, Kull B, Fredholm BB. Anoxia redistributes adenosine $A(2 A)$ receptors in $P C 12$ cells and increases receptor-mediated formation of cAMP. Naunyn Schmiedebergs Arch Pharmacol 2002; 365: 150-157.

20. Berne RM. Cardiac nucleotides in hypoxia: possible role in regulation of coronary blood flow. Am J Physiol 1963; 204: 317-322.

21. Hansen PB, Schnermann J. Vasoconstrictor and vasodilator effects of adenosine in the kidney. Am J Physiol Renal Physiol 2003; 285: F590-F599.

22. Sun D, Samuelson LC, Yang T, Huang $Y$, Paliege A, Saunders $T$ et al. Mediation of tubuloglomerular feedback by adenosine: evidence from mice lacking adenosine 1 receptors. Proc Natl Acad Sci USA 2001; 98: 9983-9988.

23. Brown R, Ollerstam A, Johansson B, Skött O, Gebre-Medhin S, Fredholm B et al. Tubuloglomerular feedback and increased plasma renin in adenosine $A 1$ receptor-deficient mice. Am J Physiol Regul Integr Comp Physiol 2001; 281: R1362-R1367.

24. Tawfik HE, Schnermann J, Oldenburg PJ, Mustafa SJ. Role of A 1 adenosine receptors in the regulation of vascular tone. Am J Physiol Heart Circ Physiol 2005; 288 $\mathrm{H} 1411-\mathrm{H} 1416$.

25. Yang J-N, Tiselius C, Daré E, Johansson B, Valen G, Fredholm BB. Gender differences in mouse heart rate and body temperature and in their regulation by adenosine $\mathrm{A} 1$ receptors. Acta Phys 2007 (in press).

26. Ledent C, Vaugeois JM, Schiffmann SN, Pedrazzini T, El Yacoubi M, Vanderhaeghen JJ et al. Aggressiveness, hypoalgesia and high blood pressure in mice lacking the adenosine A2A receptor. Nature 1997; 388: 674-678.

27. Conti B, Sanchez-Alavez M, Winsky-Sommerer R, Morale MC, Lucero J, Brownell S et al. Transgenic mice with a reduced core body temperature have an increased life span. Science 2006; 314: 825-828.

28. Sherman MY, Gabai VL. Multiple thermometers in mammalian cells: why do cells from homeothermic organisms need to measure temperature? Sci STKE 2006; 2006 (328): pe16.

29. Giménez-Llort L, Fernández-Teruel A, Escorihuela RM, Fredholm BB, Tobena A, Pekny M et al. Mice lacking the adenosine $\mathrm{A} 1$ receptor are anxious and aggressive, but are normal learners with reduced muscle strength and survival rate. Eur $J$ Neurosci 2002; 16 547-550.

30. Fredholm BB, Chen JF, Masino SA, Vaugeois JM. Actions of adenosine at its receptors in the CNS: insights from knockouts and drugs. Annu Rev Pharmacol Toxicol 2005; 45 385-412.

31. Schotanus SM, Fredholm BB, Chergui K. NMDA depresses glutamatergic synaptic transmission in the striatum through the activation of adenosine $A(1)$ receptors: evidence from knockout mice. Neuropharmacology 2006; 51: 272-282.

32. Kochanek PM, Vagni VA, Janesko KL, Washington CB, Crumrine PK, Garman $\mathrm{RH}$ et al. Adenosine $\mathrm{A} 1$ receptor knockout mice develop lethal status epilepticus after experimental traumatic brain injury. J Cereb Blood Flow Metab 2006; 26 : 565-575.

33. Fedele $\mathrm{DE}$, Li T, Lan JQ, Fredholm BB, Boison D. Adenosine $A(1)$ receptors are crucial in keeping an epileptic focus localized. Exp Neurol 2006; 200: 184-190. 
34. Gauda EB, Northington FJ, Linden J, Rosin DL. Differential expression of $A(2 A), A(1)$ adenosine and $\mathrm{D}(2)$-dopamine receptor genes in rat peripheral arterial chemoreceptors during postnatal development. Brain Res 2000; 872: 1-10.

35. Monteiro EC, Ribeiro JA. Adenosine-dopamine interactions and ventilation mediated through carotid body chemoreceptors. Adv Exp Med Biol 2000; 475: 671-684.

36. Headrick JP, Hack B, Ashton KJ. Acute adenosinergic cardioprotection in ischemic reperfused hearts. Am J Physiol Heart Circ Physiol 2003; 285: H1797-H1818.

37. Stein AB, Tang XL, Guo Y, Xuan YT, Dawn B, Bolli R. Delayed adaptation of the heart to stress: late preconditioning. Stroke 2004; 35 (Suppl 1): 2676-2679.

38. Fryer RM, Auchampach JA, Gross GJ. Therapeutic receptor targets of ischemic preconditioning. Cardiovasc Res 2002; 55: 520-525

39. Lankford AR, Yang J-N, Rose'Meyer R, French BA, Matherne GP, Fredholm BB et al. Effect of modulating cardiac $\mathrm{A} 1$ adenosine receptor expression on protection with ischemic preconditioning. Am J Physiol 2006; 290: H1469-H1473.

40. Schulte G, Sommerschild H, Yang J, Tokuno S, Goiny M, Lövdahl C et al. Adenosine A receptors are necessary for protection of the murine heart by remote, delayed adaptation to ischaemia. Acta Physiol Scand 2004; 182: 133-143.

41. Carmeliet $P$. Angiogenesis in life, disease and medicine. Nature 2005; 438: 932-936.

42. Ferrara N, Kerbel RS. Angiogenesis as a therapeutic target. Nature 2005; 438 967-974.

43. Greenberg DA, Jin K. From angiogenesis to neuropathology. Nature 2005; 438 954-959.

44. Frantz S, Vincent KA, Feron O, Kelly RA. Innate immunity and angiogenesis. Circ Res 2005; 96: 15-26.

45. Adair TH. Growth regulation of the vascular system: an emerging role for adenosine. $A m J$ Physiol Regul Integr Comp Physiol 2005; 289: R283-R296.

46. Feoktistov I, Ryzhov S, Zhong H, Goldstein AE, Matafonov A, Zeng D et al. Hypoxia modulates adenosine receptors in human endothelial and smooth muscle cells toward an A2B angiogenic phenotype. Hypertension 2004; 44: 649-654.

47. Merighi S, Benini A, Mirandola P, Gessi S, Varani K, Leung E et al. Adenosine modulates vascular endothelial growth factor expression via hypoxia-inducible factor-1 in human glioblastoma cells. Biochem Pharmacol 2006; 72: 19-31.

48. Montesinos MC, Shaw JP, Yee H, Shamamian P, Cronstein BN. Adenosine A(2A) recepto activation promotes wound neovascularization by stimulating angiogenesis and vasculogenesis. Am J Pathol 2004; 164: 1887-1892.

49. Cronstein BN. Adenosine, an endogenous anti-inflammatory agent. J Appl Physiol 1994 76: $5-13$

50. Lukashev D, Ohta A, Apasov S, Chen JF, Sitkovsky M. Cutting edge: physiologic attenuation of proinflammatory transcription by the Gs protein-coupled A2A adenosine receptor in vivo. J Immunol 2004; 173: 21-24.

51. Bours MJ, Swennen EL, Di Virgilio F, Cronstein BN, Dagnelie PC. Adenosine 5'triphosphate and adenosine as endogenous signaling molecules in immunity and inflammation. Pharmacol Ther 2006; 112: 358-404.

52. Akkari R, Burbiel JC, Hockemeyer J, Müller CE. Recent progress in the development of adenosine receptor ligands as antiinflammatory drugs. Curr Top Med Chem 2006; 6 : 1375-1399.

53. Fredholm BB. Purines and neutrophil leukocytes. Gen Pharmacol 1997; 28: 345-350.

54. Eltzschig HK, Thompson LF, Karhausen J, Cotta RJ, Ibla JC, Robson SC et al. Endogenous adenosine produced during hypoxia attenuates neutrophil accumulation: coordination by extracellular nucleotide metabolism. Blood 2004; 104: 3986-3992.

55. Yang D, Zhang Y, Nguyen HG, Koupenova M, Chauhan AK, Makitalo M et al. The A2B adenosine receptor protects against inflammation and excessive vascular adhesion. J Clin Invest 2006; 116: 1913-1923.

56. Chen Y, Corriden R, Inoue Y, Yip L, Hashiguchi N, Zinkernagel A et al. ATP release guides neutrophil chemotaxis via P2Y2 and A3 receptors. Science 2006; 314: 1792-1795.
57. Fredholm BB, Assender JW, Irenius E, Kodama N, Saito N. Synergistic effects of adenosine $A 1$ and $P 2 Y$ receptor stimulation on calcium mobilization and $P K C$ translocation in DDT1 MF-2 cells. Cell Mol Neurobiol 2003; 23: 379-400.

58. Hask G, Pacher P, Deitch EA, Vizi ES. Shaping of monocyte and macrophage function by adenosine receptors. Pharmacol Ther 2007; 113: 264-275.

59. Zernecke A, Bidzhekov K, Ozüyaman B, Fraemohs L, Liehn EA, Lüscher-Firzlaff JM et al. CD73/ecto-5'-nucleotidase protects against vascular inflammation and neointima formation. Circulation 2006; 113: 2120-2127.

60. Tsutsui S, Schnermann J, Noorbakhsh F, Henry S, Yong VW, Winston BW et al. A1 adenosine receptor upregulation and activation attenuates neuroinflammation and demyelination in a model of multiple sclerosis. J Neurosci 2004; 24: 1521-1529.

61. Sun CX, Young HW, Molina JG, Volmer JB, Schnermann J, Blackburn MR. A protective role for the $A 1$ adenosine receptor in adenosine-dependent pulmonary injury. $J$ Clin Invest 2005; 115: 35-43.

62. Schnurr M, Toy T, Shin A, Hartmann G, Rothenfusser S, Soellner J et al. Role of adenosine receptors in regulating chemotaxis and cytokine production of plasmacytoid dendritic cells. Blood 2004; 103: 1391-1397.

63. Ohta A, Sitkovsky M. Role of G-protein-coupled adenosine receptors in downregulation of inflammation and protection from tissue damage. Nature 2001; 414: 916-920.

64. Sullivan GW, Fang G, Linden J, Scheld WM. A2A adenosine receptor activation improves survival in mouse models of endotoxemia and sepsis. J Infect Dis 2004; 189: 1897-1904.

65. Lappas CM, Sullivan GW, Linden J. Adenosine A2A agonists in development for the treatment of inflammation. Expert Opin Investig Drugs 2005; 14: 797-806.

66. Lappas CM, Rieger JM, Linden J. A2A adenosine receptor induction inhibits IFN-gamma production in murine CD4+ T cells. J Immunol 2005; 174: 1073-1080.

67. Lappas CM, Day YJ, Marshall MA, Engelhard VH, Linden J. Adenosine A2A receptor activation reduces hepatic ischemia reperfusion injury by inhibiting CD1d-dependent NKT cell activation. J Exp Med 2006; 203: 2639-2648.

68. Ohta A, Gorelik E, Prasad SJ, Ronchese F, Lukashev D, Wong MK et al. A2A adenosine receptor protects tumors from antitumor T cells. Proc Natl Acad Sci USA 2006; 103: 13132-13137.

69. Caruso M, Holgate ST, Polosa R. Adenosine signalling in airways. Curr Opin Pharmacol 2006; 6: 251-256.

70. Tilley SL, Boucher RC. A1 antagonism in asthma: better than coffee? J Clin Invest 2005; 115: $13-16$

71. Mohsenin A, Blackburn MR. Adenosine signaling in asthma and chronic obstructive pulmonary disease. Curr Opin Pulm Med 2006; 12: 54-59.

72. Sun $\mathrm{CX}$, Zhong H, Mohsenin A, Morschl E, Chunn JL, Molina JG et al. Role of A2B adenosine receptor signaling in adenosine-dependent pulmonary inflammation and injury. $J$ Clin Invest 2006; 116: 2173-2182.

73. Gu Q, Ruan T, Hong JL, Burki N, Lee LY. Hypersensitivity of pulmonary C fibers induced by adenosine in anesthetized rats. J Appl Physiol 2003; 95: 1315-1324.

74. Thiel M, Chouker A, Ohta A, Jackson E, Caldwell C, Smith P et al. Oxygenation inhibits the physiological tissue-protecting mechanism and thereby exacerbates acute inflammatory lung injury. PLOS Biol 2005; 3: e174.

75. Fredholm BB. Adenosine and neuroprotection.In: Green AR, Cross AJ (eds). Neuroprotective Agents and Cerebral Ischemia. Academic Press: London, 1996,pp 259-280.

76. Olsson T, Cronberg T, Rytter A, Asztély F, Fredholm BB, Smith ML et al. Deletion of the adenosine $A 1$ receptor gene does not alter neuronal damage following ischaemia in vivo or in vitro. Eur J Neurosci 2004; 20: 1197-1204.

77. Chen JF, Huang Z, Ma J, Zhu J, Moratalla R, Standaert D et al. A(2A) adenosine receptor deficiency attenuates brain injury induced by transient focal ischemia in mice. $J$ Neurosci 1999; 19: 9192-9200.

78. Yu L, Huang Z, Mariani J, Wang Y, Moskowitz M, Chen JF. Selective inactivation or reconstitution of adenosine A2A receptors in bone marrow cells reveals their significant contribution to the development of ischemic brain injury. Nat Med 2004; 10: 1081-1087. 